\title{
Tecnologia sustentável na produção de biodiesel
}

\section{Farihan Ihsan El Malt* e Cleide Barbieri de Souza}

Centro Universitário Lusíada. Fundação Lusíada. Rua Oswaldo Cruz, 179. Boqueirão. Santos-SP, Brasil (CEP 11045-101). *E-mail: farihan_malat@hotmail.com.

Resumo. A maior parte da energia produzida no mundo é proveniente de fontes não renováveis, causando impacto ambiental negativo e malefícios para a saúde humana. Dentre várias formas sustentáveis de produção de biodiesel, a utilização do óleo vegetal usado para esta finalidade, é de grande importância para a minimização do impacto ambiental e para criar alternativas de reutilização deste composto residual, tendo em vista a diminuição do seu descarte inadequado, reduzindo assim os riscos de poluição ambiental gerados. Este trabalho teve como objetivo a produção de biodiesel utilizando uma fonte sustentável como óleo residual, pois além de ser produzido a partir de fontes limpas e renováveis é menos poluente e, neste contexto, visa ao bem do meio ambiente e consequentemente da saúde humana. 0 objetivo foi alcançado com sucesso, uma vez que o biodiesel produzido obteve resultados positivos no teste de combustão, bem como demonstrou sua funcionalidade em um motor Turbodiesel Intercooler pertencente a uma caminhonete modelo 2016 da marca KIA.

Palavras-chave: Desenvolvimento sustentável; Biodiesel; Meio ambiente.

Abstract. Sustainable technology in biodiesel production. Most of the energy produced in the world comes from non-renewable sources, causing negative environmental impact and human health hazards. Among the various forms of sustainable biodiesel production, the use of vegetable oil used for this purpose, is of great importance for the minimization of the environmental impact and to create alternatives of reuse of this residual compound, in order to reduce its inappropriate discard, reducing So the risks of environmental pollution generated. This study had the objective of producing biodiesel using a sustainable source as residual oil, because in addition to being produced from clean and renewable sources is less polluting and, in this context, aims at the good of the environment and consequently of human health. The objective was successfully reached, since the biodiesel had positive results in the combustion test, as well as demonstrated its functionality in a Turbodiesel Intercooler engine belonging to a 2016 model KIA brand truck.

Keywords: Sustainable development; Biodiesel; Environment.
Recebido:

$25 / 05 / 2019$

Aceito:

$31 / 07 / 2019$

Disponível on line:

$01 / 08 / 2019$

Publicado:

$31 / 08 / 2019$

\section{Acesso aberto}

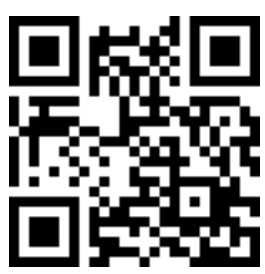

ORCID

(D) 0000-0003-3145-194X Farihan Ihsan El Malt

(D) 0000-0001-8979-4879 Cleide Barbieri de Souza 


\section{Introdução}

No século XX durante a Exposição Universal de Paris houve a aparição de um primeiro protótipo desenvolvido pelos pesquisadores Rudolph Diesel e Henry Ford, de motor movido a biocombustíveis, onde $\mathbf{o}$ mesmo era composto por óleo de amendoim. Eles pesquisaram por vários anos diversos tipos de combustíveis que pudessem diminuir o efeito devastador dos gases que eram emitidos pelos motores da época, a partir disso surgiu à ideia de criar um combustível a partir de sementes oleaginosas (Ramos et al., 2011; Rossi et al., 2018).

Atualmente a crescente demanda por energia no mundo, faz com que o biodiesel seja uma alternativa para a substituição dos combustíveis derivados do petróleo, por ser um combustível renovável, biodegradável e por emitir menos poluentes gasosos e materiais particulados. Sendo possível sua produção a partir de diversas espécies de plantas oleaginosas, que produzem óleo vegetal como: a soja, algodão, palma, mamona, girassol, canola, entre outros, como a gordura animal e óleos residuais de fritura (Ferrari e Soler, 2015; Costa et al., 2019).

A biotecnologia ambiental é uma alternativa para enfrentar a degradação do meio ambiente, visando à produção de novos combustíveis através de fontes alternativas, de forma sustentável, minimizando assim os malefícios já causados pelos combustíveis fósseis à biodiversidade (Jesus, 2005; Ladeira e Burkert, 2015).

A cada ano a quantidade de chuva ácida e poluição atmosférica gerada pelo uso de combustíveis fósseis vêm aumentando devido à emissão de gases nocivos à saúde, como enxofre e gás carbônico que causam danos irreversíveis ao sistema respiratório e até mesmo problemas cardiovasculares. Apurando este problema, a biotecnologia trouxe consigo uma inovação para obtenção de uma variedade de plantas que produzem óleo vegetal como matéria-prima, que são utilizadas para a produção de biocombustíveis que reduzem significativamente o impacto ambiental (Carrer et al., 2010; Ferrari e Soler, 2015).

O Brasil situa-se numa região extremamente privilegiada devido ao clima tropical, alta luminosidade e recursos hídricos que favorecem o crescimento de diversos tipos de vegetais que podem ser utilizados para a produção do biodiesel. A matéria-prima preferida dos produtores é a soja, mesmo contendo baixo teor de óleo, em comparação aos outros tipos de matériaprima como, por exemplo: o amendoim e a mamona, que apresentam fatores que fazem com que o retorno de investimento seja mais rápido, pois pode ser armazenado por longos períodos e não tem restrição de clima para plantio. Diversas matérias-primas também são fonte de produção para o biodiesel, sendo encontradas em diversas áreas do país, cada uma com sua particularidade de região e condições favoráveis de crescimento (Yamaoka, 2014).

0 biodiesel quando comparado ao diesel, oferece vantagens para o meio ambiente, reduzindo as emissões de partículas de carbono na forma de fumaça, monóxido de carbono, óxidos sulfúricos e hidrocarbonetos policíclicos aromáticos. Essa vantagem gera menor custo relacionado à saúde pública, visto pelo grande consumo de óleo diesel no setor do transporte (Fernandes et al., 2008; Rossi et al., 2018).

A vantagem do biodiesel é por ser um combustível biodegradável produzido a partir de fontes renováveis, como os óleos vegetais. Fator que gera empregos na área rural, evitando o êxodo e trazendo oportunidade para as regiões menos favorecidas. No entanto, a competição entre a produção de alimentos e a produção de combustível, resulta em um aumento no valor dos 
grãos elevando o custo de produção (Silva e Freitas, 2008; Rossi et al., 2018).

Uma desvantagem do biodiesel é por produzir $10 \%$ menos energia do que o óleo diesel. Entretanto, o biodiesel apresenta maior viscosidade que permite uma melhor lubricidade, resultando em diminuição do desgaste do motor (Lôbo et al., 2009).

É possível a produção do biodiesel através de óleo vegetal residual como matéria-prima, o que acarreta na diminuição satisfatória em relação à contaminação da água, tendo em vista que o óleo não será descartado inadequadamente no meio ambiente, mas utilizado como matéria-prima, pois a cada $1 \mathrm{~L}$ de óleo descartado no meio ambiente são contaminados um milhão de litros de água, tornando esta água imprópria ao consumo humano. 0 óleo quando presente na água é facilmente visto, por ser uma molécula leve e possuir menor densidade em relação à água, se localizando na superfície e sendo imiscível, formando assim uma barreira que dificulta a entrada da luz e bloqueando a oxigenação da água, ocasionando um desequilíbrio ambiental, comprometendo assim a vida aquática (Rabelo, 2008; Silva et al., 2015; Modesto et al., 2018).

Os efluentes provenientes do processo de purificação do biodiesel tornam seu descarte inapropriado pelo sistema hídrico, devido aos resíduos remanescentes do processo de lavagem. Entretanto, essa água deverá passar por um tratamento, que pode ser empregado através de processos químicos, físicos, biológicos ou eletroquímicos, como por exemplo, a adsorção, eletrofloculação, coagulação, filtração, floculação, oxidação avançada e decantação. Com o objetivo de reduzir a quantidade de resíduos presentes na água, possibilitando assim seu descarte pelo sistema hídrico sem acarretar prejuízos ao meio ambiente (Cordeiro et al., 2015).

A principal rota empregada pelas indústrias para a obtenção do biodiesel é a reação de transesterificação, ou também chamada de alcoólise. Desta forma, este processo consiste na reação entre um triglicerídeo com um álcool (metanol ou etanol) na presença de um catalisador (ácido ou básico), formando éteres alquílicos de ácidos graxos e glicerol. Entretanto, o metanol é o álcool mais utilizado devido seu baixo custo, melhor rendimento, tempo de reação e facilidade na separação do glicerol. Dentre os catalisadores, o catalisador básico é o mais empregado, em virtude do seu rendimento elevado e seletividade. Sendo eles, o hidróxido de sódio $(\mathrm{NaOH})$ e o hidróxido de potássio (KOH) (Ma e Hanna, 1999; Rebelo, 2015).

A presença de ácidos graxos livres (AGL) representa o índice de acidez do óleo residual. Na reação de transesterificação alcalina, o Índice de AGL quando presente em quantidades menores de $1 \%$ não é recomendada. No entanto, quando a quantidade de AGL estiver presente entre $1 \%$ e $6 \%$ e a matéria-prima isenta de água, a catalise básica é recomendada, acelerando o processo de reação, embora acarrete a formação de uma pequena quantidade de sabão (Silva, 2011).

Segundo Christoff (2006), o rendimento no processo de obtenção do biodiesel através de catalise básica por rota metílica obteve aproveitamento de 98\% do volume do óleo, e apresentando um rendimento em massa de $85 \%$. Mesmo a catálise básica ser a rota mais empregada, o rendimento do biodiesel poderia ser otimizado através da catálise ácida.

O objetivo do presente trabalho foi produzir biodiesel a partir de óleo vegetal residual, uma fonte renovável, empregando materiais de baixo custo e visando a alternativas para $o$ reaproveitamento do óleo residual após sua utilização, evitando seu descarte inadequado no meio ambiente.

\section{Materiais e métodos}

Para a produção de biodiesel foi utilizado o processo de transesterificação 
do óleo vegetal utilizando metanol na presença de $\mathrm{NaOH}$ como catalisador, com o intuito de criar um biocombustível para substituir o diesel de origem fóssil.

Um dos aspectos que mais afetam na conversão do éster é a razão molar do álcool associado ao triglicerídeo. A razão molar associa-se principalmente ao tipo de catalizador empregado. Em catálises ácidas, é necessária uma razão de 30:1 de butanol em relação ao óleo de soja, porém na catalise alcalina a razão é 6:1 (seis mols de álcool para um mol de óleo) para se realizar a mesma conversão em um mesmo período.

No entanto, as condições reacionais empregadas para produzir o biodiesel foram adaptadas de Bumba et al. (2015). No qual, foram utilizados 150 $\mathrm{mL}$ de óleo vegetal residual, que foi filtrado, visando a remover todas as impurezas geradas pela sua utilização no processo de fritura; e, em seguida foi aquecido até $55^{\circ} \mathrm{C}$ por aproximadamente 10 min. utilizando um bico de Bunsen, visando à remoção de toda a água presente no óleo. Em seguida, foram medidos: 0,68 g de $\mathrm{NaOH}$ que por ser um composto alcalino, proporciona um melhor rendimento em um menor tempo de reação, e $30 \mathrm{~mL}$ de metanol que permite a separação do glicerol facilmente, os quais foram misturados formando uma solução denominada de metóxido de sódio, onde ocorreu uma reação exotérmica. Esta solução foi adicionada ao óleo pouco quente, os quais, foram mantidos sob agitação por um período de $20 \mathrm{~min}$. Após a agitação, esta mistura (óleo + metóxido de sódio) foi decantada, e esta mistura foi transferida para um funil de decantação, onde permaneceu em repouso por aproximadamente $24 \mathrm{~h}$ (Figura 1).

Após o processo de decantação, a glicerina (parte inferior do funil de decantação) foi removida. Em seguida foi iniciado o processo de purificação, utilizando $30 \mathrm{~mL}$ de água destilada, no qual foi colocado no funil de decantação, agitando suavemente a mistura e deixado repousar por 15 min., e, após este período de repouso, ocorreu o processo de decantação, da primeira lavagem do biodiesel (Figura 2). Em seguida, foi retirada a água depositada no fundo do funil e medido o $\mathrm{pH}$, utilizando fitas reativas de $\mathrm{pH}$, obtendo um $\mathrm{pH}$ 9,0 (alcalino) inicialmente, e repetido este procedimento até que $\mathrm{o} \mathrm{pH}$ da água atingiu, aproximadamente, $\mathrm{pH}$ 7,0.

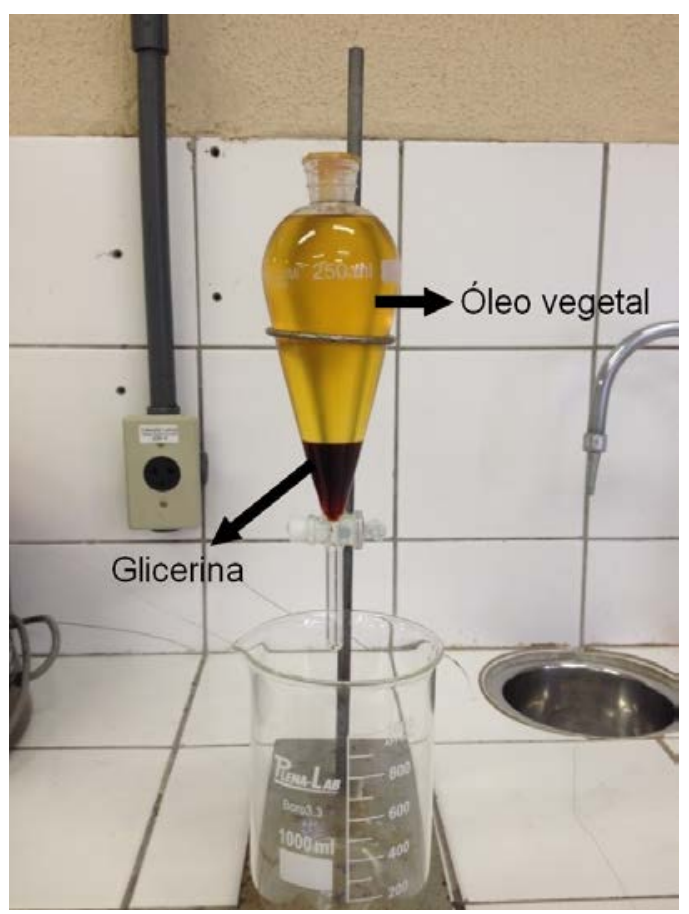

Figura 1. Etapa de separação de fase do biodiesel.

Após a retirada da glicerina, e antes do processo de purificação do biodiesel, há a necessidade da retirada do metanol residual através do processo de evaporação, utilizando um controle rígido do tempo e da temperatura, para que haja uma máxima evaporação, garantindo menores quantidades de metanol no biodiesel produzido. Neste trabalho a evaporação foi realizada após o processo de purificação, submetendo o biodiesel a uma temperatura de aproximadamente $90{ }^{\circ} \mathrm{C}$ por $10 \mathrm{~min}$. visando à evaporação tanto do metanol 
quanto de uma parcela da água remanescente do processo de lavagem. E para a retirada do catalisador, quando este for de caráter básico, é necessário a realização de uma lavagem com água acidificada $(0,5 \%$ de $\mathrm{HCl})$ a fim de neutralizar o catalisador.

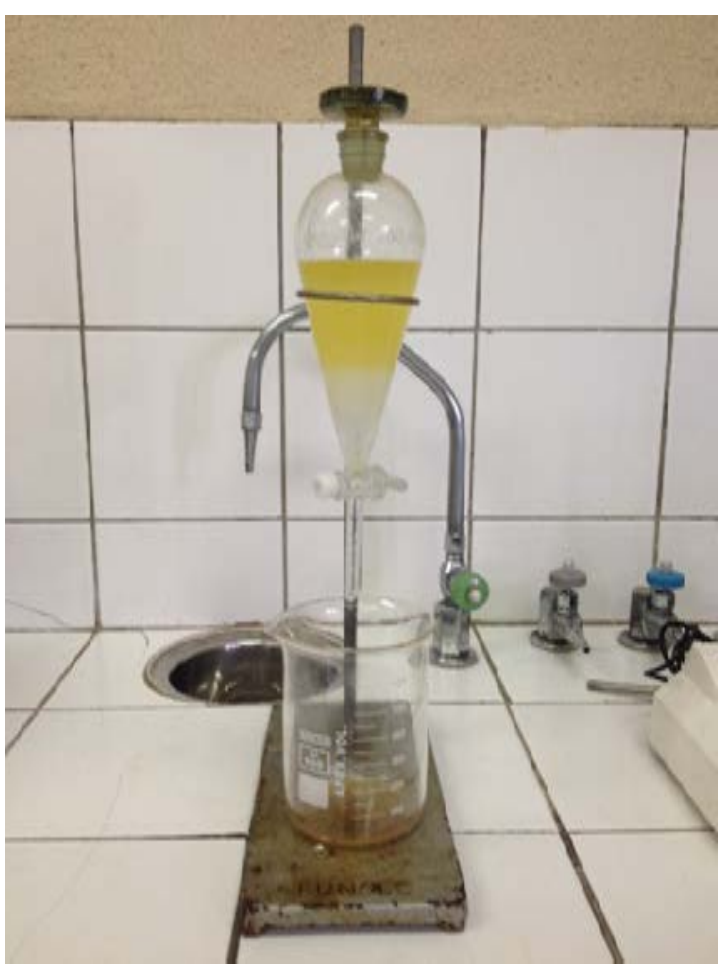

Figura 2. Processo de lavagem do biodiesel.

Para a secagem do biodiesel foi necessário a filtração da mistura utilizando papel filtro, e adicionado o sulfato de sódio anidro na mistura, deixando em contato com o biodiesel por algumas horas para eliminar os últimos resquícios de água, e novamente foi realizada a filtração para a remoção do sulfato de sódio restante, e o produto final é o biodiesel.

Após este processo de secagem, o biodiesel produzido foi utilizado para 0 teste em um motor Turbodiesel Intercooler, modelo 2016, da marca KIA, no qual foi previamente removido todo o diesel do reservatório bem como do sistema de injeção antes do teste. Desta forma, foi desconectada a mangueira que liga o tanque de combustível ao motor, sendo então adicionados 1,5 L de biodiesel diretamente no motor, com auxílio de uma mangueira.

\section{Resultados e discussão}

0 biodiesel produzido foi submetido durante o processo de produção a retirada das impurezas geradas pela sua utilização no processo de fritura, e da glicerina que é um subproduto da reação, para não afetar seu desempenho durante o processo de combustão (Figura 3).

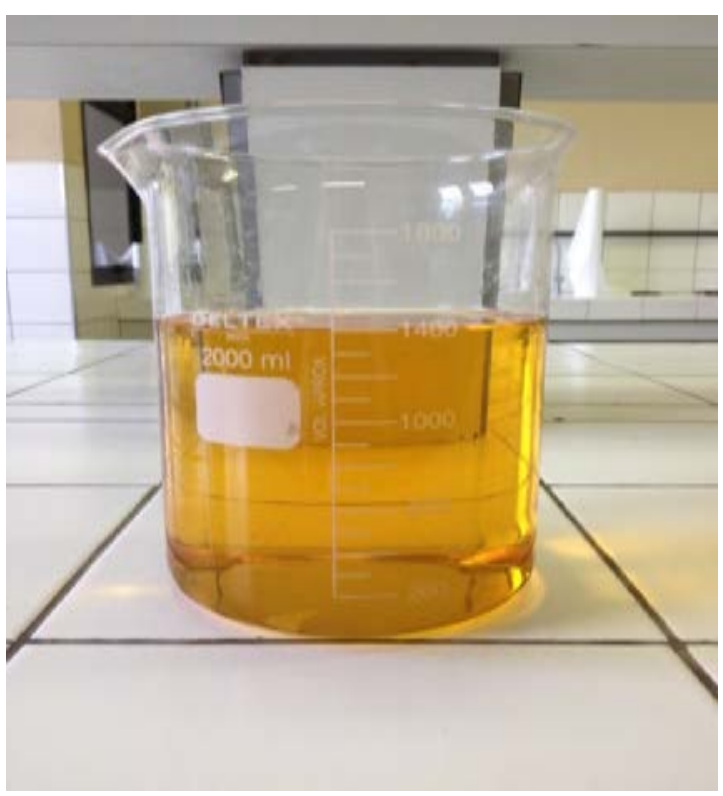

Figura 3. Biodiesel produzido.

Este biodiesel foi submetido ao teste de combustão, no qual inflamou rapidamente comparado ao óleo vegetal residual (matéria-prima usado na produção) (Figura 4). 0 teste de combustão foi realizado através da utilização de dois almofarizes (A e B), onde dentro de cada um deles foi colocado uma porção de algodão, sendo um deles encharcado com óleo residual (Figura 4-A) e o outro com biodiesel 
(Figura 4-B), e em seguida (Figura 4), foi aplicada uma fonte de calor para promoção da combustão em ambos os almofarizes, e como resultado, somente $o$ almofariz contendo o biodiesel queimou, demonstrando sua eficácia de combustibilidade.

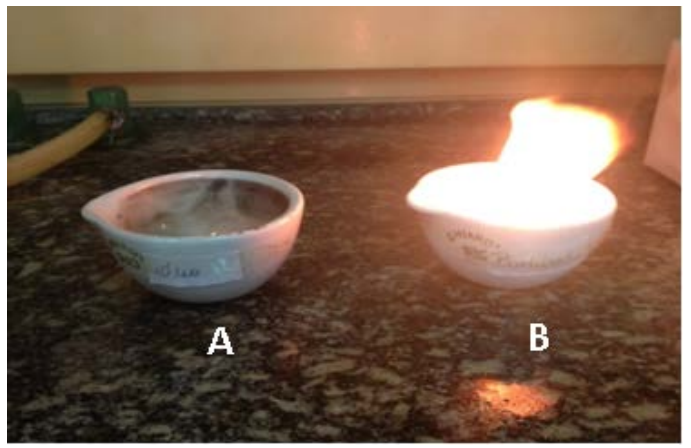

Figura 4. Teste de combustão: A) Óleo de soja; e, B) Biodiesel.

Para o teste do biodiesel, foi utilizado um motor a diesel, onde após a introdução do biodiesel produzido o funcionamento foi imediato, de forma similar ao diesel de origem fóssil.

0 custo do biodiesel ainda vem sendo um obstáculo a ser superado, devido à concorrência entre o setor alimentício com a produção de biocombustíveis, acarretando na elevação dos preços das oleaginosas e resultando em maior custo de produção do biodiesel.

Os resultados obtidos no presente estudo apontam que a eficácia do biodiesel, obtido através de matériaprima sustentável, se mostra de grande importância para o futuro do meio ambiente.

De acordo com Andrade (2017), a adição do biodiesel misturado ao óleo diesel é uma forma de diminuir a emissão de poluentes na atmosfera, principalmente pelo setor do transporte, grande responsável pela poluição do ar, minimizando assim os danos causados também ao próprio veículo.
Durante o teste realizado com o biodiesel através da utilização de um motor movido a diesel, o biodiesel mostrou ser um grande substituto do óleo diesel, desempenhando a mesma função nestes motores.

\section{Conclusão}

A importância da utilização do biodiesel, por ser um combustível produzido a partir de fontes renováveis, como o óleo vegetal usado, reduz o descarte não apropriado deste composto no meio ambiente, acarretando benefícios para o mesmo.

As vantagens do biodiesel em comparação ao óleo diesel são devido à redução na emissão de poluentes como: partículas de carbono, óxidos sulfúricos, hidrocarbonetos policíclicos aromáticos e monóxido de carbono que são tóxicos tanto ao meio ambiente quanto a saúde dos seres humanos.

Segundo os resultados obtidos neste trabalho pode-se dizer que o biodiesel produzido, alcançou $\mathrm{o}$ resultado esperado, pois após a realização do teste de combustão o biodiesel rapidamente entrou em combustão.

Os resultados obtidos através do teste de funcionalidade realizado em um motor movido a diesel, para verificar o desempenho do biodiesel produzido, houve o funcionamento do motor rapidamente de forma esperada, desempenhando um papel importante, visando futuramente à substituição do óleo diesel de origem fóssil por biocombustíveis.

De acordo com o avanço deste trabalho, concluímos que a substituição do óleo diesel pelo biodiesel pode ser um importante passo para minimizar ainda mais os danos causados ao meio ambiente e a saúde humana.

Embora não tenha sido realizada a determinação do teor de éster, não podendo comprovar sua pureza, o objetivo da obtenção do biocombustível foi alcançado, tendo em 
vista que ponto de fulgor foi atingindo e, consequentemente, gerando combustão no motor movido a óleo diesel.

\section{Agradecimentos}

Agradecemos ao Centro Universitário Lusíada pela disponibilização do laboratório e dos materiais para a elaboração deste trabalho, bem como ao Núcleo de Estudo e Pesquisa em Biotecnologia e Biologia Molecular NAPBBM.

\section{Conflito de interesses}

As autoras declaram não haver conflito de interesses.

\section{Referências}

Bumba, M. A. C.; Oi, R. K.; Yamamura, H. Produção de biodiesel a partir do óleo de fritura: uma alternativa sustentável. Blucher Chemical Engineering Proceedings, v. 1, n. 2, p. 8516-8523, 2015. https://doi.org/ 10.5151/chemeng-cobeq2014-1308-19979158693

Carrer, H.; Barbosa, A. L.; Ramiro, D. A. Biotecnologia na agricultura. Estudos Avançados, v. 24, n. 70, p. 149-164, 2010. https://doi.org/10.1590/S0103-40142010 000300010

Cordeiro, R. B.; Alexandre, J. I. S.; Silva, J. P. F.; Sales, D. C. S.; Cavalcanti, L. A. P. Purificação e reutilização de águas residuárias da produção de biodiesel por meio da eletrofloculação. Revista Brasileira de Gestão Ambiental e Sustententabilidade, v. 2, n. 2, p. 51-58, 2015.

Costa, F. R.; Costa, F. R.; Souza, A. M. N.; Goulart, V.S.; Schwanke, C. M. Sustentabilidade em ação: oficinas de produção de biodiesel. Anais do $10^{\circ}$ Salão Internacional de Ensino, Pesquisa e Extensão da UNIPAMPA, Salão de Extensão, v. 3, 2019. Disponível em: <http://seer.unipampa.edu.br/index.php/sie pe/article/view/41458>. Acesso em: 23 abr. 2019.

Christoff, P. Produção de biodiesel a partir do óleo residual de fritura comercial, estudo de caso: Guaratuba, litoral paranaense. Curitiba: LACTEC, Instituto de Tecnologia para o Desenvolvimento, 2007. (Dissertação de mestrado).

Fernandes, R. K. M.; Pinto, J. M. B.; Medeiros, O. M.; Pereira, C. A. Biodiesel a partir de óleo residual de fritura: alternativa energética e desenvolvimento sócio-ambiental. Anais do XXVIII Encontro Nacional de Engenharia de Produção: A Integração de Cadeias Produtivas com a Abordagem de Manufatura Sustentável, p. 13-16, 2008.

Ferrari, R. A.; Soler, M. P. Obtention and characterization of coconut babassu derivatives. Scientia Agricola, v. 72, n. 4, p. 291-296, 2015. https://doi.org/10.1590/ 0103-9016-2014-0278

Jesus, K. R. E. Biotecnologia ambiental: aplicações e oportunidades para o Brasil. In: Pantano Filho, R.; Rosa, D. S. (Orgs.). Meio ambiente: múltiplos olhares. Campinas: Companhia da Escola, 2005. p.171-178. Disponível em: <https://www.embrapa. $\mathrm{br} /$ meio-ambiente/busca-de-publicacoes//publicacao/14367/biotecnologiaambiental-aplicacoes-e-oportunidades-parao-brasil>. Acesso em: 23 abr. 2019.

Ladeira, B. L.; Burkert, C. A. V. Diferentes indutores para produção de lipase de Cryptococcus curvatus NRRL Y-1511 em meio contendo glicerina oriunda do biodiesel. Blucher Chemical Engineering Proceedings, v. 1, n. 2, p. 1515-1521, 2015. https://doi.org/10.5151/chemeng-cobeq 2014-1086-21113-180113

Lôbo, I. P.; Ferreira, S. L. C.; Cruz, R. S. Biodiesel: parâmetros de qualidade e métodos analíticos. Química Nova, v. 32, n. 6, p. 1596-1608, 2009. https://doi.org/ 10.1590/S0100-40422009000600044

Ma, F.; Hanna, M. A. Biodiesel production: A review. Bioresource Technology, v. 70, n. 1, p. 1-15, 1999. https://10.1016/s09608524(99)00025-5

Modesto, L. C. M. G.; Queiroz, R. O.; Faria, E. C.; Borges, D. G. Síntese de biodiesel a partir de óleo residual purificado com biomassa de banana. Revista Livre de Sustentabilidade e Empreendedorismo, v. 3, n. 2, p. 136-148, 2018.

Rabelo, R. A. Coleta seletiva de óleo residual de fritura para aproveitamento industrial. Goiânia: Universidade Católica de 
Goiás, 2008. (Trabalho de conclusão de curso).

Ramos, L. P.; Silva, F. R.; Mangrich, A. S.; Cordeiro, C. S. Tecnologias de produção de biodiesel. Revista Virtual de Química, v. 3, n. 5 , p. 385-405, 2011. https://doi.org/ 10.5935/1984-6835.20110043

Rebelo, M. D. A. Produção de biodiesel: aumento do rendimento por utilização de ácidos gordos livres residuais. Lisboa: Universidade Federal de Lisboa, 2015. (Tese de doutorado).

Rossi, G. Z.; Borges, I. R.; Perego, T. F.; Toledo, V. D. M.; Ferreira, L. F. P. Análise técnica da produção do biodiesel a partir do óleo de fritura residual. The Journal of Engineering and Exact Sciences, v. 4, n. 1, p. 101-108, 2018. https://doi.org/10.18540/jcecvl4iss1 pp0101-0108

Silva, M.; Sacardo, M.; Costa, A. E.; Andreazza, J. K. Determinação de propriedades do óleo residual de frituras, com e sem filtração, em diferentes temperaturas. Blucher Chemical Engineering Proceedings, v. 1, n. 3, p. 357-362, 2015. https://doi.org/10.5151/ chemeng-cobeqic2015-195-32767-264130
Silva, P. R. F.; Freitas, T. F. S. Biodiesel: o ônus e o bônus de produzir combustível. Ciência Rural, v. 38, n. 3, p. 843-851, 2008. https://doi.org/10.1590/S0103-84782008 000300044

Silva, T. A. R. Biodiesel de óleo residual: produção através da transesterificação por metanólise e etanólise básica, caracterização físico-química e otimização das condições reacionais. Uberlândia: Universidade Federal de Uberlândia, 2011. (Tese de doutorado).

Yamaoka, R. S. Biodiesel: matérias primas. Londrina: Secretaria do Estado da C\&T e Ensino Superior, 2014. (Dissertação de mestrado).

Informação da Licença: Este é um artigo Open Access distribuído sob os termos da Licença Creative Commons Attribution, que permite uso irrestrito, distribuição e reprodução em qualquer meio, desde que a obra original seja devidamente citada. 